\title{
Intergenerational Support in the Transition From Work to Retirement
}

\author{
Marleen Damman ${ }^{1,2}$ and Rozemarijn van Duijn ${ }^{1}$ \\ 1. Netherlands Interdisciplinary Demographic Institute (NIDI-KNAW), The Hague, The Netherlands \\ 2. University Medical Center Groningen, University of Groningen, Groningen, The Netherlands
}

\begin{abstract}
The retirement transition is often characterized by major changes in the lives of individuals. Their children could potentially offer support in this process. Little is known, however, about intergenerational support upon retirement. To what extent are parents supported by their children in the retirement process? And how can differences in the degree of support be explained? Two central theoretical frameworks from the literature on intergenerational relationships - one based on the principle of altruism and the other based on the principle of exchange-are combined with insights from the retirement literature to formulate hypotheses. These were tested by analyzing panel data collected among 697 fully retired individuals in the Netherlands. Information about support from children upon retirement (discussing retirement, and general perceived support) was collected during Wave 3 in 2011. The findings show that only a minority of the studied retirees experience support from their children in the retirement process. As expected based on the altruism principle, retirees without a partner, who have a poor financial situation, and who expected to miss the social status and finances of prior work, are relatively likely to experience support from their children upon retirement. These findings highlight the importance of taking both structural and psychological antecedents into account. Retirees who regularly look after their grandchildren, or who often help their children with practical chores, were found to experience more support as compared to retirees who never provide these types of help, which is in line with hypotheses based on the exchange perspective.
\end{abstract}

For many people retirement is a life event that involves major changes. When fully exiting the work role, retirees face the challenge to adjust to the loss of the work role and to develop a satisfactory postretirement lifestyle (Van Solinge \& Henkens, 2008). Their children could potentially-as part of the nonwork social network that often remains stable around retirement (Van Tilburg, 1992) —offer support in this process, for example, by talking with their parents about retirement. To date, however, empirical insights about intergenerational support upon retirement are scarce. Even though children are generally expected to play a role in their parents' retirement processes, the retirement literature mostly focuses on the financial restrictions that dependent children may impose on the opportunities to retire. The notion that children might also be a source of support in the retirement process has received limited attention thus far. This study is therefore designed to improve our understanding of the support that parents experience from their children upon retirement. The central research question is: To what extent are parents supported by their children in the transition from work to retirement and how can differences in the degree of support be explained?
The scientific literature about retirement assumes that the family plays an important role in people's choices and experiences regarding retirement. In a recent review article, Wang and Shultz (2010) distinguish four groups of factors that shape retirement processes: macrolevel socioeconomic factors, individual factors, job/organizational factors, and family-related factors. Within this latter group, the role of the children is studied in addition to the role of the partner. Earlier research has clearly shown that structural characteristics of the family situation (e.g., number of children, children living at home, dependent children, age of first birth) are associated with retirement processes (Hank \& Korbmacher, 2013; Litwin \& Tur-Sinai, 2015; Pienta, 2003; Raymo \& Sweeney, 2006). Generally the findings show that children may-in financial terms-form a constraint in retirement processes. Having dependent children has, for instance, been found to decrease the likelihood of (intending to) retiring early (Damman, Henkens, \& Kalmijn, 2011; Szinovacz \& DeViney, 2000; Szinovacz, DeViney, \& Davey, 2001), and to be positive related to accepting bridge employment (Kim \& Feldman, 2000). However, children could also be perceived as a potential source of support in retirement transitions. 
Even though research has been carried out into changes in people's contact with their children around the time of retirement (Szinovacz \& Davey, 2001), insights are lacking regarding the support that parents experience from their children in the transition from work to retirement and its predictors.

The broader literature about intergenerational relationships does provide ample insight into the exchange of support between parents and their adult children. Most studies show that intergenerational relationships are generally strong and that there is much provision of support, although this is dependent upon country context and life stage (Kalmijn, 2014). Support provision between parents and their children is one of the six dimensions of intergenerational solidarity (Silverstein, Bengtson, \& Lawton, 1997), and is specifically referred to as "functional solidarity." This functional solidarity (support giving) can go in both directions-i.e., from children to parents and from parents to children-and is typically distinguished into three main types (Kalmijn, 2014): instrumental support (e.g., personal care and housework), financial support (e.g., transfers of money), and emotional support (e.g., discussing life decisions). Even though the literature about intergenerational relationships provides important insights into the support received by older parents from their adult children, the support studied in this literature does not relate specifically to the retirement transition.

To examine support that older individuals experience from their children in the transition from work to retirement, this study uses a new measure of support, that includes two statements that specifically focus on the extent to which parents discuss retirement with their children (specific-behavioral), and two broader formulated statements about perceived support of children in the retirement process (general-attitudinal). In the literature on intergenerational relationships, support is frequently measured in behavioral terms, and "discussing important life decisions" is often used in these measurements as an indicator of socioemotional support (Silverstein \& Bengtson, 1994; Silverstein, Conroy, Wang, Giarrusso, \& Bengtson, 2002; Silverstein, Gans, \& Yang, 2006). In the retirement literature, earlier studies have focused on talking with the spouse and friends/coworkers about retirement (Curl \& Ingram, 2013; Ekerdt, Kosloski, \& DeViney, 2000), but little is known yet about the extent to which parents discuss the life event of retirement with their children. When parents talk with their children about retirement they could still differ, however, in the extent to which they perceive their children as being a source of support to them in the retirement process. Therefore, in the current study the two behavioral items about talking with children about retirement, were complemented with two attitudinal items measuring perceived support by children upon retirement in general terms.

This study aims to contribute to the retirement literature in two main ways. Firstly, given the lack of earlier research on intergenerational support upon retirement, this study intends to improve our understanding of the role of children in their parents' retirement processes, by providing descriptive information about the degree to which parents say they are supported by their children upon retirementmainly in socioemotional terms - in a large heterogeneous sample of retirees. Secondly, the study will contribute to the literature by providing insight into possible explanations for differences between retired people in the degree of support they experience from their children upon retirement. The literature about intergenerational relationships uses various theories to explain why children support their parents. This study will use two central theoretical perspectives from the literature about intergenerational relationships-i.e., one based on the principle of altruism and the other based on the principle of exchange - and will combine these with existing insights from the retirement literature, in order to deduce hypotheses about factors that might predict intergenerational support upon retirement. To formulate hypotheses, this study will take an interdisciplinary perspective, by paying attention to structural factors that are often central in sociological studies (e.g., resources), as well as psychological factors (e.g., retirement anxiety), which may both play a role for explaining differences in terms of support.

In the current study, the support experienced by parents from their children upon retirement is examined using panel data collected between 2001 and 2011 among almost 700 older adults who used to be employed at four large organizations in the Netherlands. As the respondents were still working in 2001 and retired fully in subsequent years, we can predict the support experienced from the children upon retirement (measured in 2011) based on preretirement factors, characteristics of the transition to retirement, and characteristics of life during retirement. An advantage of the use of panel data therefore is that various structural and psychological antecedents were measured at the time respondents were still working. In the beginning of the study period, retirement in the Netherlands was still characterized by a strong "early exit culture" (De Vroom, 2004, p. 120). The large majority of older workers retired much earlier than the public pension age, which was age 65 during the years of study. The average retirement age of employees in the Netherlands has been around age 61 between 2001 and 2007. In the years after that it increased to age 63 in 2011 (Statistics Netherlands, 2012b).

\section{THEORETICAL BACKGROUND}

In the literature about intergenerational relationships, two central theoretical perspectives are frequently used that focus on why parents and children provide support to each other (Kalmijn, 2014): one based on altruism and one based on exchange principles. By applying these theoretical perspectives to the transition from work to retirement, and by combining them with findings from the retirement literature, hypotheses about predictors of experienced support from children upon retirement can be formulated.

\section{Altruism Perspective}

In the theoretical perspective based on the principle of altruism it is assumed that family members are generally prepared to help each other if there is a need to do so, because they cherish the well-being of their family. People in need of assistance will be given support and are not expected to do anything in return (Krebs, 1970). In line with this perspective, research has shown that children respond to their parents' need for support, where factors like partnership status, health, or financial position are frequently used as (indirect) indicators of need for support (Eggebeen \& Davey, 1998; Grundy, 2005; Kalmijn \& Saraceno, 2008; Silverstein et al., 2006). For example, Kalmijn and Saraceno (2008) show in their analyses based on SHARE data that several of these indicators of need for support are associated with instrumental support elderly parents receive from their children. Parents who live without a partner, parents with a poor health situation, and 
parents with a lower status position are all found to be relatively likely to receive support from their children (Kalmijn \& Saraceno, 2008).

When applying this theoretical principle of altruism to the retirement transition, it can generally be expected that the more support parents need upon retirement, the more support they will receive from their children. Retirees differ, however, in terms of their need for support in the retirement process. While transitioning into retirement is difficult for some, others adjust to the new situation quickly and easily. Retirees also differ a lot with respect to their satisfaction with life in retirement (Van Solinge \& Henkens, 2008). When assuming that older individuals who have more difficulties adjusting to retirement and who are less satisfied with retirement are more in need of support, prior research findings about predictors of retirement adjustment and satisfaction can be used to distinguish factors that may indicate a need for support in the retirement process. Predictors that have been found to result in negative postretirement outcomes can according to this line of reasoning be expected to be associated with a higher level of intergenerational support in the retirement process. In this study we follow the structure of the explanatory model as used by Van Solinge and Henkens (2008), by examining the role of resources, retirement transition characteristics, and psychological dispositions as indicators of need for support, for explaining differences in the support parents experience from their children in the retirement process.

The research findings of Van Solinge and Henkens (2008) show that resources, such as one's partner relationship, health, and financial situation are important predictors of retirement satisfaction. Individuals who have limited resources are on average less satisfied with retirement, compared to those having access to resources. This may be due to the fact that they have relatively few means to compensate for the loss of the work role after retirement (e.g., see review by Wang, Henkens, \& Van Solinge, 2011). Resources also have been found to be key for explaining changes in terms of life satisfaction in the transition to retirement (Pinquart \& Schindler, 2007). When assuming that those individuals who have fewer resources are more in need for support upon retirement, it can be expected that retirees who do not have a partner (Hypothesis 1), are in poor health (Hypothesis 2), or have a poor financial situation (Hypothesis 3) will experience more support from their children upon retirement than those having more of these resources.

Characteristics of the retirement transition have been found to be related to postretirement outcomes as well. Earlier research has shown for example that people who worked more hours per week prior to retirement find it relatively difficult to adjust, which might be because retirement implies a major change in time commitments (Van Solinge \& Henkens, 2008), as do people who lacked control over the retirement transition or retired involuntarily (Donaldson, Earl, \& Muratore, 2010). Involuntary retirement was also found to negatively affect retirement satisfaction (Van Solinge \& Henkens, 2008), suggesting that a lack of control over the retirement transition has implications for several dimensions of the retirement process. In line with these findings we hypothesize that retirees who worked more hours per week prior to retirement (Hypothesis 4), and those who retired involuntarily (Hypothesis 5), will experience a relatively large amount of support from their children when transitioning from work to retirement.

Next to structural factors, psychological factors have been found to shape postretirement processes. Already prior to retirement, older individuals might be anxious for the changes associated with the retirement transition, for example, with regard to the impact of retirement on their social contacts, social status, or financial resources. Earlier studies have shown that in particular preretirement anxiety about the social consequences of retirement is related to difficulties adjusting to retirement, while preretirement financial anxiety was found not to be associated with postretirement adjustment and satisfaction (Van Solinge \& Henkens, 2005, 2008). Following these research findings, it can be hypothesized that older individuals who were anxious for the social consequences of retirement-i.e., who expected to miss social contacts (Hypothesis 6) or social status (Hypothesis 7) after retirementwill experience more support from their children in their retirement process than their less anxious counterparts.

\section{Exchange Perspective}

A second theoretical perspective often used in the literature about intergenerational relationships is based on the principle of exchange. This perspective assumes that the "costs" of giving others support in terms of time and energy will be compensated by the "benefits" of support received from others (Homans, 1958). The norm of reciprocity reduces uncertainty and ensures that if people give something, they will always receive something in return (Gouldner, 1960). Among parents and their children this is not, however, necessarily the same kind of support nor does it have to be exchanged at the same moment in time (Silverstein et al., 2002).

Prior research has shown that parents who give support to their children are more likely to receive help from them in return (e.g., Grundy, 2005; Klein Ikkink, Van Tilburg, \& Knipscheer, 1999). The study by Klein Ikkink and colleagues (1999) shows, for example, that there is direct reciprocity- "children's giving contingent on parent's giving" (p. 843) — in adult-child relationships and their findings suggest that this relationship between giving and receiving support cannot be explained by other characteristics of the parent-child relationship such as contact frequency, traveling time, or social norms about support provision.

Based on this line of reasoning from an exchange perspective, it can generally be expected that the more support parents provide to their children, the more support they will receive from their children upon retirement. Two central ways in which retirees might support their children are by looking after the grandchildren, and by helping their children with practical chores around the house. Based on the exchange principle it could be expected that parents who regularly look after their grandchildren (Hypothesis 8), or who often help their children with practical tasks around the house (Hypothesis 9), will experience more support from their children in their retirement process as compared to retirees who never provide these types of help.

\section{Sample}

\section{METHOD}

This research uses data from the NIDI Work and Retirement Panel, which are three-wave panel data collected by the Netherlands Interdisciplinary Demographic Institute. The first round of data collection was conducted in 2001 among older workers (50-64 years old) who at the time worked for the Dutch government or for three private sector companies. A total of 3,899 questionnaires were sent by post during the first wave; 2,403 were completed ( $62 \%$ response). Where possible, the respondents were approached again in 2006/2007 (Wave 2 ) and in 2011 (Wave 3). Some participants could not be approached 
again because of company takeovers, because of death, or because they could not be traced. In 2006/2007 a total of 2,239 questionnaires were sent out, 1,678 of which were completed (75\% response). In 2011 , 1,276 of the 1,638 questionnaires sent were completed and returned (78\% response). A large percentage of the respondents had retired by the time of the second and third wave.

The items about experienced support from one's children upon retirement were asked in the third data collection wave and were put to respondents who were fully retired at the time. The base sample for this study therefore consists of 754 respondents who were fully retired at the time of the third wave of data collection (they made use of an [early] retirement arrangement during the research period and did not report any hours of paid work) and who had one or more children. Respondents who did not answer all four items of the dependent variable $(n=57)$ have been excluded from the analyses. The analytical sample therefore consists of 697 respondents. These respondents had been retired for an average of 5.5 years at Wave 3 .

\section{Measures}

\section{Dependent variable}

During the third wave of data collection the fully retired respondents were presented with four Likert items with five answer categories $(1=$ completely agree to $5=$ completely disagree; reversely coded in the analyses) about the support from their children in the transition from work to retirement. The items focus on the extent to which parents discuss retirement with their children, and the extent to which parents perceive their children as a source of support in the retirement process (Table 1). Given that these items form a newly developed measure (instead of an existing measuring instrument), we used an exploratory factor analysis to inspect the measure. This exploratory factor analysis (principal factors method) showed one factor with an eigenvalue larger than 1 (eigenvalue $=1.54$ ), which suggests that the items measure a single underlying concept. The scale to measure support experienced from children upon retirement was constructed using the average value of the scores on the four items (Cronbach's alpha $=.73$ ). Table 2 shows the correlations between the items as well as item-test correlations. The higher the score on the scale, the more support parents say they experience from their children in the transition from work to retirement.

\section{Independent variables}

To measure resources, we focus on both the resources at the wave prior to the respondent's retirement, as well as changes in resources over time. Partner status - i.e., whether the respondent lived with a partner during the retirement transition-was measured by combining questions about the pre- and postretirement partner status of the respondent. The variable has four categories: continuously had a partner during the retirement transition (i.e., lived with a partner both pre- and postretirement, reference group), continuously had no partner, lost partner, and repartnered. The respondent's subjective health prior to retirement was measured by asking the question "How would you characterize your health in general?" $(1=$ very poor to $5=$ very good $)$. Health decline was measured at Wave 3 by the question: "Did your health change during the last five years?" ( $0=$ no change/ health improvement, $1=$ health decline). The respondent's financial situation (wealth) prior to retirement was measured by the question "How large do you estimate your total wealth (own house, savings, stocks, and so on minus debts/ mortgage) to be?" In the analyses the natural logarithm of the reported class averages is used. Financial decline was measured at Wave 3 by the question: "Are you much worse off financially after you stopped working, or not?" ( 0 = little or no financial decline, 1 = (severe) financial decline).

With respect to transition characteristics, the number of working hours was determined using data about the number of hours respondents had worked per week at the wave prior to the respondent's retirement (not including overtime hours). Whether the transition to retirement was perceived as being involuntary was measured by asking the question: "Was your decision to retire entirely voluntary or not?" For this, we used the measurement taken immediately after retirement (Wave 2 if the respondent retired between $\mathrm{T} 1$ and $\mathrm{T} 2$; Wave 3 if the respondent retired between $\mathrm{T} 2$ and $\mathrm{T} 3$ ). The answers were coded into a dummy variable, where a value of 1 indicated that the respondent had retired involuntarily.

Preretirement anxiety about the consequences of retirement, was measured at the wave prior to retirement by asking the respondents about the extent to which they expect negative consequences of retirement in several work-related domains. The question was "Could you indicate for the following aspects to what extent you expect to miss these when you are retired?" ( $1=$ not at all to $5=$ very $m u c h)$. Retirement anxiety with regard to social contacts via work and financial resources (i.e., money/income) was measured by one-item indicators. Retirement anxiety with regard to social status was constructed by taking the average value on items about self-esteem and prestige/status (cf., Van Solinge \& Henkens, 2008; Cronbach's alpha = .79).

How frequently respondents look after their grandchildren was measured during Wave 3 by asking the question "Do you ever look after your grandchildren?" The answer categories to this question were: no; yes, several times a week; yes, about once a week; yes, about once a month; yes, a few times a year; n.a., I do not have grandchildren. In the analyses, these categories were coded into four groups: respondents

Table 1. Descriptive Statistics of Items Measuring Experienced Support From Children Upon Retirement (in Percentages); $N=697$

\begin{tabular}{|c|c|c|c|c|c|}
\hline Item (Translated From Dutch) & $\begin{array}{l}\text { Completely } \\
\text { Disagree }\end{array}$ & Disagree & $\begin{array}{l}\text { Neither } \\
\text { Agree nor } \\
\text { Disagree }\end{array}$ & Agree & $\begin{array}{l}\text { Completely } \\
\text { Agree }\end{array}$ \\
\hline 1. I have talked a lot with my children about life after my retirement & 18.8 & 46.1 & 25.0 & 9.6 & 0.6 \\
\hline 2. My children often ask me what it's like to have stopped working & 15.5 & 41.0 & 30.3 & 12.8 & 0.4 \\
\hline $\begin{array}{l}\text { 3. My children are a great support to me, now that I do not work } \\
\text { anymore }\end{array}$ & 11.6 & 22.2 & 43.9 & 19.1 & 3.2 \\
\hline $\begin{array}{l}\text { 4. If I had not had children, life after my retirement would have } \\
\text { been much more difficult }\end{array}$ & 23.7 & 29.7 & 26.5 & 16.6 & 3.4 \\
\hline
\end{tabular}




\begin{tabular}{|c|c|c|c|c|}
\hline & \multicolumn{3}{|c|}{$\begin{array}{l}\text { Correlations Between } \\
\text { Items From Scale }\end{array}$} & \multirow[t]{2}{*}{$\begin{array}{l}\text { Item-Test } \\
\text { Correlation }^{\mathrm{a}}\end{array}$} \\
\hline & 1. & 2. & 3. & \\
\hline 1. I have talked a lot with my children about life after my retirement & & & & .75 \\
\hline 2. My children often ask me what it’s like to have stopped working & .53 & & & .71 \\
\hline 3. My children are a great support to me, now that I do not work anymore & .40 & .33 & & .75 \\
\hline 4. If I had not had children, life after my retirement would have been much more difficult & .37 & .32 & .50 & .77 \\
\hline
\end{tabular}

aThe item-test correlation reflects the correlation between the scale to measure "experienced support from children upon retirement" and the separate items from the scale.

with grandchildren who never look after their grandchildren (reference group), those who sometimes look after their grandchildren (once a month or a few times a year), those who look after them often (once or several times a week) and respondents without grandchildren. Whether the respondents give their children practical support was determined in Wave 3 by asking the question "Do you ever help your children with practical chores, such as tasks around the home or housework?" Here too, the categories "several times a week" and "once a week" were grouped together. The categories "once a month" and "a few times a year" were kept separate because the latter category was relatively large.

\section{Control variables}

This study controls for various characteristics of the respondent and his or her family situation, such as gender $(0=$ man, $1=$ woman $)$, number of children, and having financially dependent children during Wave $3(0=n o, 1=y e s$, financially dependent children), which was measured by the question "Do you have children who are still financially dependent?" In addition, the respondent's age at Wave 3, the number of years that have passed since retirement, and the organization the respondent used to work for were taken into account. The descriptive statistics of the independent variables and control variables are presented in Table 3.

\section{Analyses}

Linear regression analyses were applied to test the hypotheses. The number of missing values on the independent and control variables was low (generally below $1.9 \%$, only on the preretirement wealth variable the percentage was higher [4.6\%]). The missing values were imputed using a multiple imputation procedure (Stata 12: mi impute chained). The variables with missing values were imputed 25 times by using the information of the dependent, independent, and control variables. The regression model was then estimated for all these 25 datasets and the results were combined (Stata 12: mi estimate).

\section{RESULTS}

\section{Descriptive Results}

The descriptive statistics of the items to measure support experienced from children upon retirement are presented in Table 1. The results generally show that only a minority of the respondents say they are supported by their children upon retirement. About $10 \%$ say they have often talked about life after retirement with their children, and 13\% say that their children often ask them what it's like to have stopped working. Of the respondents, $22 \%$ indicate that their children are a great support to them, now that they no longer work. About $20 \%$ indicate that life after retirement would have been much more difficult if they had not had children. When combining answers to the various statements (not shown in the table) it appears that no more than $6 \%$ of the respondents (completely) agree with three or all four statements about support upon retirement. About $61 \%$ did not agree with any of the statements, which suggests that they experience little support from their children in the transition from work to retirement.

\section{Multivariate Results}

Table 4 shows the results of the multivariate regression analyses estimated to explain differences in the level of support experienced from children upon retirement. To test the hypotheses based on the altruism perspective, in Model 1 the role of resources is first examined. Generally, it was expected that the fewer resources parents have, in terms of their partner status, health situation, and financial situation, the more support they will experience from their children upon retirement. The results for partner status and financial resources are in line with Hypotheses 1 and 3. Retired people who do not have a partnerboth those who do not have a partner pre- and postretirement, and those who lost their partner during the period of study-experienced more support from their children upon retirement than those who continuously had a partner. Moreover, parents who had a poorer preretirement wealth situation, were more likely to experience support from their children upon retirement. The effect of experiencing a financial decline after retirement is in the expected direction (a financial decline is associated with more support), but is not statistically significant at the 5\% level. The respondent's health situation was not associated with support experienced from the children upon retirement.

In Model 2, the retirement transition characteristics were added to the equation. The effects of the number of hours worked prior to retirement, and involuntary retirement were, however, not statistically significant. Preretirement anxiety about the consequences of retirement was associated with intergenerational support upon retirement though (Model 3). It was expected that older individuals who were anxious for the social consequences of retirement, are relatively like to experience support of their children in the retirement process. In line with Hypothesis 7, the results show that the more older individuals expected to miss the social status of work after retirement, the more likely they are to experience support from their children upon retirement. For social contacts, the expected effect was not observed. We did find an association for financial retirement anxiety: the more older individuals expected to miss money/income after retirement, the more likely they are to experience support from their children upon retirement. 
Table 3. Descriptive Statistics of the Dependent, Independent, and Control Variables ${ }^{a}$

\begin{tabular}{|c|c|c|}
\hline Variable & $M / \%$ & $S D$ \\
\hline \multicolumn{3}{|l|}{ Dependent variable } \\
\hline Support from children upon retirement (range 1-5) & 2.49 & 0.73 \\
\hline \multicolumn{3}{|l|}{ Indicators of need for support } \\
\hline \multicolumn{3}{|l|}{ Resources } \\
\hline \multicolumn{3}{|l|}{ Partner status (pre- and postretirement) } \\
\hline Continuously had partner (reference group) & $88 \%$ & \\
\hline Continuously had no partner & $7 \%$ & \\
\hline Lost partner & $4 \%$ & \\
\hline Repartnered & $2 \%$ & \\
\hline Health prior to retirement (range $1-5$ ) & 4.01 & 0.85 \\
\hline Health decline & $32 \%$ & \\
\hline $\begin{array}{l}\text { Log wealth prior to retirement (range } \\
7.73-13.25 \text { ) }\end{array}$ & 11.50 & 1.45 \\
\hline Financial decline & $48 \%$ & \\
\hline \multicolumn{3}{|l|}{ Transition characteristics } \\
\hline Working hours prior to retirement (range $8-40$ ) & 36.27 & 7.24 \\
\hline Involuntary retirement & $30 \%$ & \\
\hline \multicolumn{3}{|l|}{ Psychological factors } \\
\hline $\begin{array}{l}\text { Retirement anxiety prior to retirement: } \\
\text { social contacts (range } 1-5 \text { ) }\end{array}$ & 2.78 & 1.02 \\
\hline $\begin{array}{l}\text { Retirement anxiety prior to retirement: } \\
\text { status (range } 1-5 \text { ) }\end{array}$ & 1.59 & 0.71 \\
\hline $\begin{array}{l}\text { Retirement anxiety prior to retirement: } \\
\text { financial (range 1-5) }\end{array}$ & 2.77 & 0.97 \\
\hline \multicolumn{3}{|l|}{ Indicators of exchange of support } \\
\hline \multicolumn{3}{|l|}{ Looking after grandchildren } \\
\hline Never (reference group) & $11 \%$ & \\
\hline About once a month/a few times a year & $32 \%$ & \\
\hline About once a week/several times a week & $35 \%$ & \\
\hline n.a., no grandchildren & $22 \%$ & \\
\hline \multicolumn{3}{|l|}{ Practical support } \\
\hline Never (reference group) & $23 \%$ & \\
\hline A few times a year & $49 \%$ & \\
\hline About once a month & $16 \%$ & \\
\hline About once a week/several times a week & $12 \%$ & \\
\hline \multicolumn{3}{|l|}{ Control variables } \\
\hline Gender: woman & $22 \%$ & \\
\hline \multicolumn{3}{|l|}{ Number of children } \\
\hline 1 child (reference group) & $15 \%$ & \\
\hline 2 children & $64 \%$ & \\
\hline 3 children & $15 \%$ & \\
\hline 4+ children & $6 \%$ & \\
\hline Financially dependent children & $8 \%$ & \\
\hline Age (range 60-75) & 65.06 & 2.77 \\
\hline Years since retirement (range $0-10$ ) & 5.49 & 2.76 \\
\hline \multicolumn{3}{|l|}{ Organization } \\
\hline Public sector (reference group) & $38 \%$ & \\
\hline Private sector 1 & $19 \%$ & \\
\hline Private sector 2 & $24 \%$ & \\
\hline Private sector 3 & $20 \%$ & \\
\hline
\end{tabular}

aThe descriptive statistics are based on the values prior to imputation of missing values.
To test the hypotheses based on the exchange perspective, it was examined whether parents who often help their children-by looking after the grandchildren (Hypothesis 8) or by helping out with practical tasks around the home (Hypothesis 9)-experience more support upon retirement than parents who do not offer their children these kinds of support. The results as presented in Model 4 are in line with Hypotheses 8 and 9. Retired people who look after their grandchildren were found to experience more support from their children upon retirement than respondents who never look after their grandchildren. We also found that retired people without grandchildren received more support than those who did have grandchildren but never looked after them. Retirees who help their children with practical chores around the home experience more support from their children upon retirement than parents who never do so. The more frequently they do so, the larger the effect is.

Various control variables were also found to be related to perceived support from children upon retirement. Parents with children who still depend on them financially tend to receive less support in the transition to retirement than parents who do not have financially dependent children, although in Model 4 this effect is no longer statistically significant at a 5\% level. The number of children also plays a role: parents with three children on average say they receive more support than parents who have one child. No difference was found between men and women in the level of support experienced from their children in the transition from work to retirement.

To check the robustness of the study findings, as additional analyses we ran the statistical model separately with a measure of 'discussing retirement with children' (average value on two specific-behavioral items) and 'perceived general support of children in the retirement process' (average value on two general-attitudinal items), as dependent variables. Even though the exploratory factor analysis indicated one factor underlying the four items, from a conceptual viewpoint it might be relevant to distinguish between these dimensions and to see whether the effects of the independent variables are found for both dimensions. The results in Table 5 generally show that similar precursors are of importance for understanding the two dimensions of support. The loss of a partner, anxiety about the loss of social status after retirement, and frequently providing help to children (looking after grandchildren or practical support), are associated with more talking about retirement with children, as well as with more perceived general support of children in the retirement process. The effects of various indicators of the respondent's financial situation-i.e., limited wealth and financial retirement anxiety-were only significantly related to the behavioral dimension of discussing retirement with the children.

\section{DISCUSSION}

Retirement is an important transition in the lives of older individuals. Despite the fact that earlier research has shown that choices and experiences surrounding retirement are related to having children and the life situation of these children (e.g., whether they are still financially dependent), little is known about the extent to which children are a source of support to their parents in the retirement process. In order to provide greater insight into this phenomenon, this study explicitly asked retirees about the support they experienced from their children in the retirement process. Our results from the Netherlands show that 
Table 4. Results of Multivariate Regression Analyses to Explain Experienced Support From Children Upon Retirement, Coefficients, and Standard Errors $(N=697)$

\begin{tabular}{|c|c|c|c|c|c|c|c|c|}
\hline & \multicolumn{2}{|l|}{ Model 1} & \multicolumn{2}{|l|}{ Model 2} & \multicolumn{2}{|l|}{ Model 3} & \multicolumn{2}{|l|}{ Model 4} \\
\hline & Coefficient & $S E$ & Coefficient & $S E$ & Coefficient & $S E$ & Coefficient & $S E$ \\
\hline Constant & $1.77^{*}$ & 0.81 & $1.94^{*}$ & 0.83 & $1.84^{*}$ & 0.82 & 0.77 & 0.80 \\
\hline \multicolumn{9}{|l|}{ Indicators of need for support } \\
\hline \multicolumn{9}{|l|}{ Partner status (ref. = had partner pre- and postretirement) } \\
\hline Continuously had no partner & $0.29^{*}$ & 0.12 & $0.31^{* *}$ & 0.12 & $0.20^{+}$ & 0.12 & $0.24^{*}$ & 0.11 \\
\hline Lost partner & $0.28^{*}$ & 0.14 & $0.29^{*}$ & 0.14 & $0.28^{*}$ & 0.14 & $0.37^{* *}$ & 0.14 \\
\hline Repartnered $^{a}$ & -0.03 & 0.21 & -0.01 & 0.21 & -0.07 & 0.21 & 0.05 & 0.20 \\
\hline Health prior to retirement & 0.03 & 0.03 & 0.03 & 0.03 & 0.02 & 0.03 & 0.01 & 0.03 \\
\hline Health decline & 0.01 & 0.06 & 0.00 & 0.06 & -0.04 & 0.06 & -0.03 & 0.06 \\
\hline Wealth prior to retirement $(\log )$ & $-0.04^{*}$ & 0.02 & $-0.04^{*}$ & 0.02 & $-0.05^{*}$ & 0.02 & $-0.04^{*}$ & 0.02 \\
\hline Financial decline & $0.10^{+}$ & 0.06 & $0.10^{+}$ & 0.06 & 0.05 & 0.06 & 0.06 & 0.05 \\
\hline Working hours prior to retirement & & & -0.01 & 0.01 & -0.00 & 0.01 & -0.00 & 0.01 \\
\hline Involuntary retirement & & & 0.05 & 0.06 & 0.01 & 0.06 & 0.02 & 0.06 \\
\hline Retirement anxiety prior to retirement: social contacts & & & & & 0.04 & 0.03 & 0.01 & 0.03 \\
\hline Retirement anxiety prior to retirement: status & & & & & $0.18^{* *}$ & 0.04 & $0.19^{* *}$ & 0.04 \\
\hline Retirement anxiety prior to retirement: financial & & & & & $0.06^{*}$ & 0.03 & $0.06^{*}$ & 0.03 \\
\hline \multicolumn{9}{|l|}{ Indicators of exchange of support } \\
\hline \multicolumn{9}{|l|}{ Looking after grandchildren (ref. = never) } \\
\hline About once a month/a few times a year & & & & & & & $0.19^{*}$ & 0.09 \\
\hline About once a week/several times a week & & & & & & & $0.48^{* *}$ & 0.09 \\
\hline n.a., no grandchildren & & & & & & & $0.26^{* *}$ & 0.10 \\
\hline \multicolumn{9}{|l|}{ Practical support (ref. $=$ never $)$} \\
\hline A few times a year & & & & & & & $0.18^{* *}$ & 0.07 \\
\hline About once a month & & & & & & & $0.29^{* *}$ & 0.09 \\
\hline About once a week/several times a week & & & & & & & $0.34^{* *}$ & 0.09 \\
\hline \multicolumn{9}{|l|}{ Control variables } \\
\hline Gender: woman & 0.05 & 0.08 & 0.00 & 0.10 & -0.01 & 0.10 & 0.05 & 0.09 \\
\hline \multicolumn{9}{|l|}{ Number of children (ref. = 1 child) } \\
\hline 2 children & $0.15^{+}$ & 0.08 & $0.14^{+}$ & 0.08 & $0.16^{*}$ & 0.08 & 0.12 & 0.08 \\
\hline 3 children & $0.26^{*}$ & 0.10 & $0.25^{*}$ & 0.10 & $0.28^{* *}$ & 0.10 & $0.23^{*}$ & 0.10 \\
\hline $4+$ children & 0.09 & 0.13 & 0.07 & 0.13 & 0.09 & 0.13 & 0.08 & 0.13 \\
\hline Financially dependent children & $-0.22^{*}$ & 0.11 & $-0.22^{*}$ & 0.11 & $-0.23^{*}$ & 0.10 & $-0.19^{+}$ & 0.10 \\
\hline Age & 0.01 & 0.01 & 0.02 & 0.01 & 0.01 & 0.01 & 0.02 & 0.01 \\
\hline Years since retirement & $-0.02^{+}$ & 0.01 & $-0.02^{+}$ & 0.01 & -0.01 & 0.01 & -0.01 & 0.01 \\
\hline \multicolumn{9}{|l|}{ Organization (ref. $=$ public sector) } \\
\hline Private sector 1 & 0.13 & 0.08 & 0.12 & 0.08 & 0.11 & 0.08 & 0.11 & 0.08 \\
\hline Private sector 2 & -0.08 & 0.08 & -0.08 & 0.08 & -0.11 & 0.08 & -0.12 & 0.08 \\
\hline Private sector 3 & 0.08 & 0.09 & 0.06 & 0.09 & 0.05 & 0.09 & -0.01 & 0.09 \\
\hline$F$ & $3.32^{* *}$ & & $3.05^{* *}$ & & $4.51^{* *}$ & & $6.13^{* *}$ & \\
\hline
\end{tabular}

${ }^{a}$ The group of repartnered respondents is very small $(n=12)$, so the coefficients should be interpreted with caution. ${ }^{+} p<.10 ;{ }^{*} p<.05 ;{ }^{* *} p<.01$.

Data source: NIDI Work and Retirement Panel. Missing values were imputed by a multiple imputation procedure.

only a minority of the studied retirees experience support from their children in the retirement process. Just a small group of the studied retirees were found to talk about retirement with their children (which is an indication of socioemotional support), or to generally perceive their children as an important source of support in the transition from work to retirement. About $60 \%$ of the retirees did not answer positively to any of the statements about support from their children and therefore seem to experience little support from them in the retirement process.
These findings are remarkable, given that the retirement literature shows that the retirement transition is widely shared with another close family member, namely with the partner. Retirement is a topic that many older workers talk about with their partner (Ekerdt et al., 2000) and partners have been clearly shown to influence retirement decision making (Henkens, 1999; Henkens \& Van Solinge, 2002; Szinovacz \& DeViney, 2000). Retirees without a partner (e.g., because of a divorce) are a vulnerable group in the retirement process. Earlier research has shown, for instance, that they are relatively 
Table 5. Results of Multivariate Regression Analyses to Explain Specific and General Support From Children Upon Retirement, Coefficients, and Standard Errors $(N=697)$

\begin{tabular}{|c|c|c|c|c|}
\hline & \multicolumn{2}{|c|}{$\begin{array}{l}\text { Support: } \\
\text { Specific-Behavioral }^{\mathrm{a}}\end{array}$} & \multicolumn{2}{|c|}{$\begin{array}{l}\text { Support: } \\
\text { General_Attitudinal }{ }^{\mathrm{b}}\end{array}$} \\
\hline & Coefficient & $S E$ & Coefficient & $S E$ \\
\hline Constant & 1.42 & 0.91 & 0.12 & 1.01 \\
\hline \multicolumn{5}{|l|}{ Indicators of need for support } \\
\hline \multicolumn{5}{|l|}{ Partner status (ref. = had partner pre- and post retirement) } \\
\hline Continously had no partner & $0.24^{+}$ & 0.13 & $0.25^{+}$ & 0.14 \\
\hline Lost partner & $0.31^{*}$ & 0.15 & $0.44^{*}$ & 0.17 \\
\hline Repartnered $^{c}$ & 0.29 & 0.23 & -0.19 & 0.25 \\
\hline Health prior to retirement & 0.06 & 0.04 & -0.03 & 0.04 \\
\hline Health decline & -0.08 & 0.06 & 0.02 & 0.07 \\
\hline Wealth prior to retirement $(\log )$ & $-0.05^{*}$ & 0.02 & -0.02 & 0.02 \\
\hline Financial decline & 0.05 & 0.06 & 0.07 & 0.07 \\
\hline Working hours prior to retirement & -0.00 & 0.01 & -0.00 & 0.01 \\
\hline Involuntary retirement & 0.00 & 0.07 & 0.05 & 0.07 \\
\hline Retirement anxiety prior to retirement: social contacts & 0.01 & 0.03 & 0.01 & 0.04 \\
\hline Retirement anxiety prior to retirement: status & $0.14^{* *}$ & 0.05 & $0.25^{* *}$ & 0.05 \\
\hline Retirement anxiety prior to retirement: financial & $0.07^{*}$ & 0.03 & 0.05 & 0.04 \\
\hline \multicolumn{5}{|l|}{ Indicators of exchange of support } \\
\hline \multicolumn{5}{|l|}{ Looking after grandchildren (ref. = never) } \\
\hline About once a month/a few times a year & 0.13 & 0.10 & $0.26^{*}$ & 0.11 \\
\hline About once a week/several times a week & $0.37^{* *}$ & 0.10 & $0.60^{* *}$ & 0.12 \\
\hline n.a., no grandchildren & $0.20^{+}$ & 0.11 & $0.32^{*}$ & 0.12 \\
\hline \multicolumn{5}{|l|}{ Practical support (ref. $=$ never $)$} \\
\hline A few times a year & $0.17^{*}$ & 0.08 & $0.19^{*}$ & 0.09 \\
\hline About once a month & $0.22^{*}$ & 0.10 & $0.36^{* *}$ & 0.11 \\
\hline About once a week/several times a week & $0.25^{*}$ & 0.11 & $0.43^{* *}$ & 0.12 \\
\hline \multicolumn{5}{|l|}{ Control variables } \\
\hline Gender: woman & -0.06 & 0.11 & 0.15 & 0.12 \\
\hline \multicolumn{5}{|l|}{ Number of children (ref. = 1 child) } \\
\hline 2 children & 0.08 & 0.09 & 0.16 & 0.10 \\
\hline 3 children & $0.21^{+}$ & 0.11 & $0.25^{*}$ & 0.12 \\
\hline 4+ children & -0.06 & 0.14 & 0.22 & 0.16 \\
\hline Financially dependent children & -0.10 & 0.12 & $-0.28^{*}$ & 0.13 \\
\hline Age & 0.01 & 0.01 & $0.02^{+}$ & 0.01 \\
\hline Years since retirement & $-0.03^{*}$ & 0.01 & 0.00 & 0.01 \\
\hline \multicolumn{5}{|l|}{ Organization (ref. $=$ public sector $)$} \\
\hline Private sector 1 & 0.11 & 0.09 & 0.11 & 0.10 \\
\hline Private sector 2 & -0.10 & 0.09 & -0.13 & 0.09 \\
\hline Private sector 3 & -0.05 & 0.10 & 0.03 & 0.11 \\
\hline 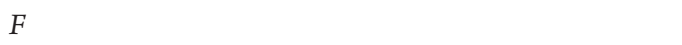 & $3.87^{* *}$ & & $5.82^{* *}$ & \\
\hline
\end{tabular}

aBased on the average value of the scores on the items: "I have talked a lot with my children about life after my retirement" and "My children often ask me what it's like to have stopped working."

bBased on the average value of the scores on the items: "My children are a great support to me, now that I do not work anymore" and "If I had not had children, life after my retirement would have been much more difficult."

"The group of repartnered respondents is very small $(n=12)$, so the coefficients should be interpreted with caution.

Data source: NIDI Work and Retirement Panel. Missing values were imputed by a multiple imputation procedure.

${ }^{+} p<.10 ;{ }^{*} p<.05 ;{ }^{* *} p<.01$.

likely to miss the social contacts and social status of work after retirement (Damman, Henkens, \& Kalmijn, 2015). The findings of the current study show that rather these retirees without a partner-those who continuously did not have a partner, and those who recently lost their partner-experience a relatively high level of support from their children upon retirement. In light of the literature, these findings might suggest that older individuals generally rely on their partner for support in the retirement process, and turn to their children when a partner is lacking or when the partner cannot provide the support that is needed. 
These results are in line with expectations based on altruism theory, in which it was hypothesized that parents who were in greater need of support would also receive more support from their children upon retirement. Next to partnership status, this study examined the role of various other factors that have been found in earlier research to predict negative postretirement outcomes in terms of adjustment and satisfaction, and therefore were assumed to indicate a need for support: resources (poor health, poor financial situation), retirement transition characteristics (work hours, involuntary retirement), and psychological factors (retirement anxiety). The lack of a partner, limited wealth, anxiety to miss work-related social status, and anxiety to miss workrelated financial resources, were associated with more support from children in the retirement process. These results suggest that especially social and financial needs are of importance for explaining differences in the degree of intergenerational support upon retirement. The findings highlight as well the importance of taking an interdisciplinary perspective, by examining both structural and psychological antecedents simultaneously. Given a specific structural situation, individuals might differ in the way they evaluate the consequences of retirement (cf., Henkens, 1999), and both structural factors and evaluations are found to affect the support parents experience from their children upon retirement. The expected effects of a poor preretirement health situation, the experience of a health decline, working hours prior to retirement, and involuntary retirement were, however, not observed in this study. This could mean that children did not act upon these parental needs for support, that these parents did not seek support from their children, or that parents needed other types of support from their children than captured by the dependent variable of the current study (e.g., parents with health problems might especially have been in need for instrumental support). It could also be the case, however, that the various indirect measurements used to determine the need for support in this study, were not good indicators of the actual need for support upon retirement.

Not only the theoretical principle of altruism, but also the principle of exchange appeared to be relevant for understanding which parents were more likely to experience support from their children upon retirement. Based on the exchange principle, it was expected that parents who give their children more support will also receive more support when transitioning into retirement. The results are in line with this hypothesis. The more frequently parents look after their grandchildren, the more support they experience from their children upon retirement. Parents who frequently help their children with chores around the home were also found to experience more support from their children. Still, the theoretical question remains whether this can be explained by the exchange principle of direct reciprocity. Another explanation is that both offering support and receiving support are strongly related to the frequency of contact between parents and children, the distance between places where parents and children live, the quality of the relationship, or certain values within families, and therefore offering support and receiving support might be associated indirectly. A limitation of the current study is that these possible underlying factors were not measured, given that the collected data focused on the themes of work and retirement. An important direction for future research is therefore to further disentangle these mechanisms in the context of intergenerational support upon retirement. It should be mentioned though, that in earlier research on intergenerational instrumental support, the effect of direct reciprocity remained intact when controlling for these types of potential underlying factors (Klein Ikkink et al., 1999). Also no information was available about the level of support parents provided to their children earlier in life (Silverstein et al., 2002) and therefore it was not possible to test the notion of long-term reciprocity.

A noteworthy finding is that the gender of the parent was not associated with the level of intergenerational support upon retirement. This is remarkable, given that in the literature on intergenerational relationships it is frequently shown that women receive more instrumental (Kalmijn, 2007; Kalmijn \& Saraceno, 2008) as well as socioemotional support (Kalmijn, 2007; Umberson, 1992) from their children as compared to men, which is generally attributed to the differential investments that men and women make to the parental role over the life course. An explanation of the lack of a gender difference in terms of intergenerational support upon retirement is the potentially selective character of the women included in the study sample. At the first wave of data collection in 2001, the net labor participation rate of older women (aged 50-64) in the Netherlands was only $30 \%$ (Statistics Netherlands, 2012a). Therefore, the women included in the sample - who used to work during their late careers — are most likely a highly work-oriented group, who might not differ that much from men in terms of their investments in the parental role over the life course and the implications of retirement.

When interpreting the current study findings, several limitations of the study should be kept in mind. Firstly, despite the fact that the availability of information about the support from children upon retirement and the availability of both behavioral and attitudinal items is strength of the data, the measurement of the dependent variable also has several shortcomings. For example, the support given was measured only among the parents. It may well be that the level of support reported by the parents is not the same as the level that would have been reported by the children (Klein Ikkink et al., 1999). Furthermore, the scale consists of a limited number of items, in two of these items the type of support is not specified, and the items do not capture all potential dimensions of intergenerational support as distinguished in the literature on intergenerational relationships (Kalmijn, 2014). Even though in case of the transition into retirement, socioemotional support from the children may be more central than instrumental or financial support, it would be informative to examine these dimensions simultaneously and see whether this notion is reflected in the data. Moreover, the behavioral items could be further improved by measuring support provision by children more directly. The current item "I have talked a lot with my children about life after my retirement," might mainly reflect the respondent's efforts, rather than the willingness or efforts of the children to talk with their parents about retirement. Yet another limitation of the dependent variable is that intergenerational support upon retirement was only measured at the third wave of data collection. Important directions for future research would be to further develop the scale of intergenerational support upon retirement, to validate it in other study samples, and to examine changes in terms of support over time. A second study limitation is that not only the items about support from the children upon retirement, but also several predictor variables (e.g., the support parents give to their children) were solely measured during the third wave of data collection. This makes it impossible to draw conclusions about the causality of these relationships studied. Further, most of the predictor variables were based on single-item indicators. A third drawback is that the data were collected among former employees of four large organizations. The sample is 
therefore not necessarily representative of the total population of retired people in the Netherlands.

Despite these limitations, this study is an important first step toward a better understanding of the support parents experience from their children-mainly in socioemotional terms - in the transition from work to retirement. Overall, in our study retirement appears to be a life transition in which children are not so much involved. An important question for future research is whether this is a missed opportunity for the exchange of support. To what extent do older individuals feel the need to talk about retirement or to receive other forms of support upon retirement? From whom would they want to receive support, from whom do they actually receive support, and how is the support experienced by the retiree? Examining the broader social network of the older individual-not solely focusing on the children but also taking the partner, friends, acquaintances, former colleagues, siblings, and other relevant actors into account-would be a valuable direction for future research. Another important question focuses on the link between support provision and well-being. Previous research has shown that when people experience important life events, such as the death of a partner or health deterioration, support received from one's children has a positive influence on the parent's well-being (Silverstein \& Bengtson, 1994). Whether this also is the case in the retirement process, is an important question to be addressed in future research.

\section{ACKNOWLEDGMENTS}

This work was supported by the Netherlands Organization for Scientific Research NWO [VICI Grant 453-14-001 to K.H.] and Netspar.

\section{REFERENCES}

Curl, A. L., \& Ingram, J. G. (2013). Anticipatory socialization for retirement: A multilevel dyadic model. Clinical Gerontologist, 36, 375-393. doi:10.1080/07317115.2013.788117

Damman, M., Henkens, K., \& Kalmijn, M. (2011). The impact of midlife educational, work, health, and family experiences on men's early retirement. The Journals of Gerontology, Series B: Psychological Sciences and Social Sciences, 66, 617-627. doi:10.1093/geronb/gbr092

Damman, M., Henkens, K., \& Kalmijn, M. (2015). Missing work after retirement: The role of life histories in the retirement adjustment process. The Gerontologist, 55, 802-813. doi:10.1093/geront/ gnt169

De Vroom, B. (2004). The shift from early to late exit: Changing institutional conditions and individual preferences. The case of the Netherlands. In T. Maltby, B. De Vroom, M. L. Mirabile, \& E. Overbye (Eds.), Ageing and the transition to retirement. A comparative analysis of European welfare states (pp. 120-154). Aldershot, $\mathrm{UK}$ : Ashgate.

Donaldson, T., Earl, J. K., \& Muratore, A. M. (2010). Extending the integrated model of retirement adjustment: Incorporating mastery and retirement planning. Journal of Vocational Behavior, 77, 279289. doi:10.1016/j.jvb.2010.03.003

Eggebeen, D. J., \& Davey, A. (1998). Do safety nets work? The role of anticipated help in times of need. Journal of Marriage and the Family, 60, 939-950. doi:10.2307/353636
Ekerdt, D. J., Kosloski, K., \& DeViney, S. (2000). The normative anticipation of retirement by older workers. Research on Aging, 22, 3-22. doi: $10.1177 / 0164027500221001$

Gouldner, A. W. (1960). The norm of reciprocity: A preliminary statement. American Sociological Review, 25, 161-178. doi: $10.2307 / 2092623$

Grundy, E. (2005). Reciprocity in relationships: Socio-economic and healthinfluences on intergenerational exchanges between Third Age parents and their adult children in Great Britain. The British Journal of Sociology, 56, 233-255. doi:10.1111/j.1468-4446.2005.00057.x

Hank, K., \& Korbmacher, J. M. (2013). Parenthood and retirement. Gender, cohort, and welfare regime differences. European Societies, 15, 446-461. doi:10.1080/14616696.2012.750731

Henkens, K. (1999). Retirement intentions and spousal support: A multi-actor approach. The Journals of Gerontology, Series B: Psychological Sciences and Social Sciences, 54, 63-73. doi:10.1093/ geronb/54B.2.S63

Henkens, K., \& Van Solinge, H. (2002). Spousal influences on the decision to retire. International Journal of Sociology, 32, 55-74.

Homans, G. C. (1958). Social behavior as exchange. American Journal of Sociology, 63, 597-606. doi:10.1086/222355

Kalmijn, M. (2007). Gender differences in the effects of divorce, widowhood and remarriage on intergenerational support: Does marriage protect fathers? Social Forces, 85, 1079-1104. doi:10.1353/ sof.2007.0043

Kalmijn, M. (2014). Adult intergenerational relationships. In J. Treas, J. Scott, \& M. Richards (Eds.), The Wiley-Blackwell companion to the sociology of families (pp. 385-403). New York: Wiley-Blackwell.

Kalmijn, M., \& Saraceno, C. (2008). A comparative perspective on intergenerational support. Responsiveness to parental needs in individualistic and familialistic countries. European Societies, 10, 479-508. doi:10.1080/14616690701744364

Kim, S., \& Feldman, D. C. (2000). Working in retirement: The antecedents of bridge employment and its consequences for quality of life in retirement. The Academy of Management Journal, 43, 11951210. doi: $10.2307 / 1556345$

Klein Ikkink, K., Van Tilburg, T., \& Knipscheer, K. C. P. M. (1999). Perceived instrumental support exchanges in relationships between elderly parents and their adult children: Normative and structural explanations. Journal of Marriage and Family, 61, 831844. doi: $10.2307 / 354006$

Krebs, D. L. (1970). Altruism: An examination of the concept and a review of the literature. Psychological Bulletin, 73, 258-302. doi: $10.1037 / \mathrm{h} 0028987$

Litwin, H., \& Tur-Sinai, A. (2015). The role of the social network in early retirement among older Europeans. Work, Aging and Retirement, 1, 340-349. doi:10.1093/workar/wav013

Pienta, A. M. (2003). Partners in marriage: An analysis of husbands' and wives' retirement behavior. The Journal of Applied Gerontology, 22, 340-358. doi:10.1177/0733464803253587

Pinquart, M., \& Schindler, I. (2007). Changes of life satisfaction in the transition to retirement: A latent-class approach. Psychology and Aging, 22, 442-455. doi:10.1037/0882-7974.22.3.442

Raymo, J. M., \& Sweeney, M. M. (2006). Work-family conflict and retirement preferences. The Journals of Gerontology, Series B: 
Psychological Sciences and Social Sciences, 61, 161-169. doi:10.1093/ geronb/61.3.S161

Silverstein, M., \& Bengtson, V.L. (1994). Does intergenerational social support influence the psychological well-being of older parents? The contingencies of declining health and widowhood. Social Science of Medicine, 38, 943-957. doi:10.1016/0277-9536(94)90427-8

Silverstein, M., Bengtson, V. L., \& Lawton, L. (1997). Intergenerational solidarity and the structure of adult child-parent relationships in American families. American Journal of Sociology, 103, 429-460. doi:10.1086/231213

Silverstein, M., Conroy, S. J., Wang, H., Giarrusso, R., \& Bengtson, V. L. (2002). Reciprocity in parent-child relations over the adult life course. The Journals of Gerontology, Series B: Psychological Sciences and Social Sciences, 57, 3-13. doi:10.1093/geronb/57.1.S3

Silverstein, M., Gans, D., \& Yang, F. M. (2006). Intergenerational support to aging parents. The role of norms and needs. Journal of Family Issues, 27, 1068-1084. doi:10.1177/0192513X0628 8120

Statistics Netherlands. (2012a). Arbeidsdeelname; 15 jaar of ouder [Labor participation; age 15 and older]. Retrieved July 5, 2012 from http://statline.cbs.nl/statweb/

Statistics Netherlands. (2012b). Van arbeid naar pensioen; personen 55 jaar of ouder [From work to retirement; persons age 55 and older]. Retrieved April 12, 2012 from http://statline.cbs.nl/StatWeb/

Szinovacz, M. E., \& Davey, A. (2001). Retirement effects on parentadult child contacts. The Gerontologist, 41, 191-200. doi:10.1093/ geront/41.2.191
Szinovacz, M. E., \& DeViney, S. (2000). Marital characteristics and retirement decisions. Research on Aging, 22, 470-498. doi:10.1177/0164027500225002

Szinovacz, M. E., DeViney, S., \& Davey, A. (2001). Influences of family obligations and relationships on retirement variations by gender, race, and marital status. The Journals of Gerontology, Series B: Psychological Sciences and Social Sciences, 56, 20-27. doi:10.1093/ geronb/56.1.S20

Umberson, D. (1992). Relationships between adult children and their parents: Psychological consequences for both generations. Journal of Marriage and Family, 54, 664-674. doi:10.2307/353252

Van Solinge, H., \& Henkens, K. (2005). Couples' adjustment to retirement: A multi-actor panel study. The Journals of Gerontology, Series B: Psychological Sciences and Social Sciences, 60, 11-20. doi:10.1093/geronb/60.1.S11

Van Solinge, H., \& Henkens, K. (2008). Adjustment to and satisfaction with retirement: two of a kind? Psychology and Aging, 23, 422-434. doi:10.1037/0882-7974.23.2.422

Van Tilburg, T. (1992). Support networks before and after retirement. Journal of Social and Personal Relationships, 9, 433-445. doi:10.1177/0265407592093006

Wang, M., Henkens, K., \& Van Solinge, H. (2011). Retirement adjustment. A review of theoretical and empirical advancements. American Psychologist, 66, 204-213. doi:10.1037/a0022414

Wang, M., \& Shultz, K. S. (2010). Employee retirement: A review and recommendations for future investigation. Journal of Management, 36, 172-206. doi:10.1177/0149206309347957 